\title{
Peningkatan Pelayanan Calon Penumpang Kapal Studi Kasus di Perusahaan Pelayaran
}

\author{
Eni Tri Wahyuni ${ }^{a^{*}}$, Aan Rubiyanto ${ }^{b}$ \\ ${ }^{\text {a,b }}$ Politeknik Bumi Akpelni \\ a*Email: enitriwahyuni85@gmail.com \\ bEmail: aan@akpelni.ac.id
}

\begin{abstract}
ABSTRAK
Perusahaan pelayaran yang bergerak di bidang pelayanan sangat memperhatikan para pengguna jasa. Salah satunya perusahaan yang bergerak di bidang pelayanan jasa terutama di kapal penumpang sangat memperhatikan kepuasan para pengguna jasa untuk keberlangsungan perusahaan tersebut. Penelitian ini bertujuan untuk mengetahui bagaimana pelayanan penumpang di PT Atosim Lampung Pelayaran yang diterapkan di Pelabuhan Tanjung Emas Semarang. Diharapkan dengan pelayanan yang baik waktu pelayanan penumpang akan lebih cepat dan efisien. Namun dalam proses pelayanan penumpang di PT Atosim Lampung Pelayaran Cabang Semarang masih mengalami beberapa hambatan yang memengaruhi pelayanan calon penumpang. Hambatan tersebut disebabkan antara lain: kurang pahamnya pembeli tiket dalam memesan tiket dan pengecekan jadwal secara online, kurang efektifnya pelayanan kesehatan di PT Atosim Lampung Pelayaran cabang Semarang. Metode penelitian yang digunakan adalah metode penelitian kualitatif dengan melakukan wawancara, observasi, dan studi pustaka. Penelitian ini menemukan bahwa dalam upaya meningkatkan pelayanan terhadap calon penumpang kapal, PT Atosim Lampung Pelayaran melakukan pengembangan sistem pemesanan tiket secara online dan melakukan peningkatan pelayanan fasilitas kesehatan.
\end{abstract}

Kata Kunci : pelayanan kapal di dermaga, pelayanan calon penumpang

\begin{abstract}
Shipping companies engaged in services are very concerned about service users. One of the companies engaged in services, especially on passenger ships, is very concerned about the satisfaction of service users for the sustainability of the company. This study aims to find out how the passenger service at PT Atosim Lampung Pelayaran is implemented at the Port of Tanjung Emas Semarang. It is hoped that with good service, passenger service time will be faster and more efficient. However, in the process of serving passengers at PT Atosim Lampung Shipping Semarang branch is still experiencing several obstacles that affect the service of prospective passengers. These obstacles are caused, among others: lack of understanding of ticket buyers in ordering tickets and checking schedules online, ineffective health services at PT Atosim Lampung Shipping Semarang branch. The research method used is a qualitative research method by conducting interviews, observations and literature studies. This study found that in order to improve services to prospective ship passengers, PT Atosim Lampung Pelayaran developed an online ticket booking system and improved health facility services.
\end{abstract}

Keywords: ship service at the pier, prospective passenger service passenger

\section{PENDAHULUAN}

Transportasi mempunyai peran yang sangat penting dalam mengembangkan Negara Indonesia. Salah satu transportasi yang sering digunakan adalah transportasi laut (Rodrigue, 2017), Transportasi Laut ini sangat penting untuk menghubungkan pulau-pulau yang tersebar (Boyce, 2011) di seluruh Indonesia. Salah satu sarana transportasi laut adalah angkutan laut yang berupa kapal. Kapal adalah kendaraan pengangkut penumpang dan barang di laut. Angkutan kapal laut 
merupakan usaha perusahaan pelayaran yang bergerak dalam bidang penyedia jasa angkutan laut. Jasa angkutan laut meliputi jasa angkutan penumpang dan jasa angkutan barang (Naletina \& Perkov, 2017). Peranan perusahaan pelayaran sangatlah penting bagi dunia pelayaran di Indonesia. PT Atosim Lampung Pelayaran merupakan perusahaan yang bergerak dalam bidang pelayaran. PT Atosim Lampung Pelayaran adalah perusahaan nasional yang menyediakan jasa angkutan transportasi laut, meliputi jasa angkutan penumpang dan angkutan barang antar pulau. Untuk melaksanakan kebijakan pemerintah, maka dibukalah kantor cabang PT Atosim Lampung Pelayaran di beberapa wilayah Indonesia, termasuk juga di Semarang. Kapal yang dioperasikan oleh PT Atosim Lampung cabang Semarang adalah kapal untuk angkutan Penumpang dan barang yang sering disebut kapal RORO Fery.

Setiap perusahaan mempunyai tujuan untuk tetap bisa bertahan dan berkembang. Tujuan tersebut dapat dicapai melalui usaha mempertahankan dan meningkatkan laba perusahaan serta melakukan strategi yang sesuai agar dapat menggunakan peluang yang ada dalam pemasaran, pelayanan, sampai pada titik kepuasan pelanggan (Santhanalaxmi \& Chandramohan, 2020). Untuk itu PT Atosim Lampung Pelayaran sedang melakukan berbagai upaya untuk perbaikan di antaranya memperbaiki kualitas dalam hal kepuasan pelanggan dan loyalitas penumpang (Mathisen \& Solvoll, 2010).

Pelanggan memiliki harapan yang begitu besar terhadap pelayanan perusahaan. Sebagai produsen atau penyedia jasa kita harus mampu memberikan pelayanan prima kepada pelanggan bukan hanya sekedar layanan yang baik, akan tetapi mampu memuaskan pelanggan (COLESCA, PACESILA, BURCEA, CIOCOIU, \& BUGHEANU, 2017). Pelayanan prima sendiri mempunyai arti yaitu suatu sikap atau tata cara pihak customer service (pelayanan pelanggan) dapat melayani pelanggan secara memuaskan. Kepuasan pelanggan adalah hasil yang dirasakan oleh pembeli atau pengguna jasa yang mengalami kinerja sebuah perusahaan yang sesuai dengan harapannya. Pelanggan merasa puas jika harapan mereka terpenuhi, dan merasa amat gembira jika harapan mereka melebihi dengan harapan yang diinginkan (Tuan, Vu, \& Nhan, 2018). Pelanggan yang puas cenderung tetap akan menggunakan jasa lebih lama, membeli atau menggunakan jasa lebih banyak, tidak akan menghiraukan terhadap perubahan harga dan akan memberikan informasi yang menguntungkan bagi perusahaan (Miremadi, Ghalamkari, \& Sadeh, 2011).

Masalah pelayanan sebenarnya bukanlah hal yang sulit atau rumit, tetapi apabila hal ini kurang diperhatikan maka dapat menimbulkan hal-hal yang rawan karena sifatnya yang sensitif (Teshome, 2017). Seperti kurangnya sosialisasi sistem online terhadap masyarakat membuat masyarakat kurang memahami, memesan dan mengecek jadwal kapal. Apabila sosialisasi lebih ditingkatkan hal ini akan menguntungkan dua pihak yaitu karyawan PT Atosim Lampung Pelayaran akan terbantu dalam pekerjaannya dan masyarakat akan lebih cepat dan aman dalam memesan tiket (UNCTAD, 2019). Meningat pentingnya layanan kepada penumpang, maka penulis mengambil judul Upaya Peningkatan Pelayanan Calon Penumpang Kapal Milik PT Atosim Lampung Pelayaran di Pelabuhan Tanjung Emas Semarang. Menurut penelitian terdahulu yang berjudul Evaluasi Pelayanan Penumpang di Pelabuhan Pontianak Provinsi Kalimantan Barat (Arief Hidayat, 2019) penelitian tersebut mengkaji tentang tingkat kepuasan dan rekomendasi yang diberikan untuk meningkatkan kinerja pelayanan di 
terminal penumpang pelabuhan Pontianak.

\section{METODE}

Metode penelitian ini menggunakan teknik wawancara semi terstruktur, observasi dan studi pustaka dalam pengumpulan data. Menurut Smith (2009), wawancara terstruktur dibagi menjadi 2 (dua) tipe yaitu: 1.Wawancara Terstruktur Penyelidik, menentukan secara pasti apa saja data yang diperlukan. Langkah berikutnya adalah mengkonstruksi pertanyaan-pertanyaan sedemikian rupa untuk mendapatkan jawabanjawaban yang sesuai, dan memuaskan kategori-kategori yang telah ditetapkan, yang dapat dianalisis secara numerical. 2. Wawancara Semi Terstruktur Penyelidik, memiliki seperangkat pertanyaan pada daftar wawancara, tapi wawancara akan dipandu oleh daftar tersebut, bukan didikte. Dalam hal ini peneliti mewawancarai secara langsung manager operasional PT Atosim Lampung Pelayaran.

\section{HASIL DAN PEMBAHASAN}

Pelayanan merupakan kegiatan yang dilakukan oleh seseorang maupun kelompok orang untuk memenuhi kebutuhan orang lain sesuai dengan prosedur dan sistem yang telah ditetapkan sebelumnya. PT Atosim Lampung Pelayaran cabang Semarang berusaha untuk meningkatkan pelayanan dan kemudahan kepada para penumpang dengan cara sebagai berikut.

Belum adanya aplikasi pemesanan tiket secara online di PT Atosim Lampung Pelayaran. Pemesanan tiket yang dilakukan pada saat itu dengan cara sistem manual. Penerapan sistem tersebut mengharuskan para calon penumpang memesan tiket kapal ke kantor cabang terdekat atau melalui agen penjual tiket. Kurang maksimalnya sistem tersebut mengakibatkan antrian panjang di depan kantor, selain itu tidak semua penumpang bertempat tinggal di dekat kantor cabang.

Untuk meminimalisir hal tersebut PT Atosim Lampung Pelayaran menerapkan sistem online dalam pemesanan tiket. Di dalam sistem tersebut terdapat banyak informasi mengenai harga tiket, tanggal keberangkatan, tujuan keberangkatan dan sebagainya. Namun masyarakat belum sepenuhnya memahami tentang sistem online yang telah diterapkan oleh PT Atosim Lampung Pelayaran. Sehingga mereka harus tetap datang langsung ke kantor cabang PT Atosim Lampung Pelayaran untuk membeli atau menanyakan informasi tiket. Hal ini dapat disimpulkan sisten online yang diberlakukan PT Atosim Lampung Pelayaran tidak maksimal.

Banyak kerugian apabila sistem online tidak dimanfaatkan dengan baik, di antaranya karyawan harus bekerja secara ekstra untuk melayani calon pembeli tiket yang banyak. Melayani dalam bentuk pembelian tiket atau hanya sekedar menanyakan jadwal kapal. Proses pemesanan tiket akan lebih cepat dan aman untuk dilakukan dan juga waktu yang dibutuhkan menjadi lebih praktis apabila hal tersebut dilakukan secara online. Karena masyarakat hanya menunjukkan code booking dan identitas diri kepada petugas untuk mencetak tiket yang dipesan melalui sistem online.

Upaya peningkatan pelayanan yang dilakukan selanjutnya adalah dengan memperbaiki pelayanan di fasilitas kesehatan. Fasilitas kesehatan merupakan pelayanan yang wajib terpenuhi untuk menjamin keselamatan ketika melakukan pelayanan, maka dari itu PT Atosim Lampung Pelayaran menyediakan fasilitas kesehatan tersebut untuk seluruh penumpang yang telah melakukan chek-in mandiri. Proses pemeriksaan kesehatan dilakukan jika para calon penumpang ingin memeriksakan kesehatannya, jadi tidak keseluruhan calon penumpang di periksa kesehatannya satu per satu. 
Tetapi hanya beberapa yang memiliki penyakit bawaan, sebagai contoh penumpang yang memiliki penyakit asma.

Pada saat melakukan survei di pelabuhan tanjung emas Semarang, penulis mendapatkan kejadian ditemukannya seseorang manula yang memiliki penyakit asma ketika sedang melakukan cek kesehatan. Dengan ditemukannya penyakit tersebut, petugas kesehatan tidak mengijinkan manula tersebut mengikuti pelayaran. Tidak hanya di ruang tunggu saja, perusahaan juga memfasilitasi pelayanan kesehatan di atas kapal. Pelayanan kesehatan menjadi terkendala pada saat petugas yang bertanggungjawab di bagian kesehatan seringkali tidak berada di posisi untuk berjaga. Hal tersebut mengakibatkan tidak terlaksananya kegiatan tersebut dengan baik, sehingga penumpang yang ingin mengecek kesehatannya ketika menaiki kapal tidak jadi melakukan pemeriksaan kesehatan.

Upaya yang dilakukan untuk meningkatkan pelayanan kenyamanan dan kemudahan bagi para calon penumpang kapal milik PT Atosim Lampung Pelayaran adalah dengan melakukan sosialisasi sebelum penumpang di embarkasikan dan menyebarkan brosur mengenai tata cara pemesanan tiket online melalui handphone. Dengan sistem online dapat mempersingkat lamanya untuk mendapatkan tiket sehingga masyarakat harus memahami tentang sisten online yang diterapkan oleh PT Atosim Lampung Pelayaran. Dengan pahamnya masyarakat tentang sistem online maka masyarakat akan lebih jelas dan mudah dalam mendapatkan informasi tentang tiket dan proses dalam pencetakan tiket menjadi lebih praktis dan pekerjaan menjadi lebih cepat selesai. Dengan mensosialisasikan sistem online kepada masyarakat maka masyarakat akan lebih paham mengenai sistem online.

Ada berbagai macam cara mensosialisasikan sistem online.
Pertama adalah sosialisasi tertulis (baliho, sepanduk, brosur). Sosialisasi ini berupa gambar atau poster. Dengan ini masyarakat dapat membaca langsung tentang sistem online yang diterapkan PT Atosim Lampung Pelayaran. Sehingga masyarakat akan lebih mudah memahaminya. Ataupun sosialisasi dengan menggunakan iklan melalui media elektronik. Masyarakat yang biasanya menggunakan media elektronik seperti TV,HP, Radio, akan lebih cepat mengetahui sistem online yang telah diterapkan oleh PT Atosim Lampung Pelayaran. Cara kedua adalah dengan sosialisasi lisan. Sosialisasi ini dengan menggunakan alat indra mulut, dapat mengadakan pertemuan di gedung, lapangan, jalan raya atau tempat lain. Yang tujuannya untuk memberi masyarakat tentang adanya sisten online. Sosialisasi ini biasanya dilaksanakan secara beramai-ramai agar dapat memikat perhatian masyarakat. Sosialisasi ini dapat juga dilakukan dari mulut ke kemulut. Masyarakat yang lebih tau biasanya memberitahu kepada masyarakat yang belum tahu, sehingga masyarakat akan lebih cepat dalam memahami tentang sistem pembelian tiket secara online yang di terapkan oleh PT Atosim Lampung Pelayaran.

Memberi fasilitas kesehatan secara gratis untuk memastikan kenyamanan dan keselamatan penumpang, PT Atosim Lampung Pelayaran telah menerapkan Peraturan Menteri Perhubungan Nomor 37 Tahun 2015 tentang Standar Pelayanan Penumpang. Pada pasal 5 ayat (20 yang berisi : pelayanan keselamatan di atas kapal sebagaimana dimaksud pada ayat (1) huruf a, meliputi informasi dan fasilitas keselamatan serta informasi dan fasilitas kesehatan.

Semua itu dilakukan untuk memberikan pelayanan yang baik dan menjamin keselamatan serta kenyamanan calon penumpang. Selanjutnya memberikan penegasan yang harus dilakukan terhadap petugas yang menyimpang, upaya penegasan 
yang dimaksud disini adalah berupa sanksi yang sesuai dalam peraturan dan hukum yang berlaku, apabila sudah ada teguran lisan dari atasan, maupun sesama petugas pelayanan, agar saling mengingatkan, menjaga dan meningkatkan ketertiban pelabuhan.

\section{SIMPULAN}

Dalam penelitian ini dapat disimpulkan bahwa dalam upaya meningkatkan pelayanan terhadap calon penumpang kapal, PT Atosim Lampung Pelayaran melakukan pengembangan sistem pemesanan tiket secara online dan melakukan peningkatan pelayanan fasilitas kesehatan. Dalam meningkatkan pelayanan calon penumpang kapal milik PT Atosim Lampung Pelayaran masih ditemukan beberapa kendala yaitu PT Atosim Lampung Pelayaran masih kurang dalam mensosialisasikan sistem pembelian tiket secara online dan tidak efektifnya pelayanan informasi dan fasilitas kesehatan di tempat sehingga masyarakat atau pelanggan tidak tahu dengan sistem pembelian tiket secara online. Untuk mengatasi kendala tersebut PT Atosim Lampung Pelayaran mengadakan sosialisai pembelian tiket secara online dan menginfokan kepada calon penumpang mengenai fasilitas kesehatan.

\section{DAFTAR PUSTAKA}

Arief Hidayat1, T. J. (2019). Evaluasi Pelayanan Penumpang di Pelabuhan Pontianak Provinsi Kalimantan Barat. Jurnal Ilmiah Nasional Sekolah Tinggi Ilmu Pelayaran Jakarta, 15-24.

https://doi.org/10.36101/msm.v $12 \mathrm{i} 1.58$

Boyce, D. (2011). Transportation Systems. Transportation Engineering and Planning, $I$.

COLESCA, S. E., PACESILA, M., BURCEA, S. G., CIOCOIU, C. N., \& BUGHEANU, A. M. (2017). Analysis of
Passenger's Satisfaction with The Quality of The Public Transportation Mode Choices in Bucharest: A Fuzzy Approach. Economic Computation and Economic Cybernetics Studies and Research, 51(5).

Mathisen, T. A., \& Solvoll, G. (2010, June). Service Quality Aspects in Ferry Passenger Transport Examples from Norway. EJTIR, 10(2), 142-157.

Miremadi, A., Ghalamkari, S., \& Sadeh, F. (2011). Customer Satisfaction in Port Industry (A Case Study of Iranian Shipping). 2011 International Conference on Sociality and Economics Development IPEDR. 10, pp. 58-62. Singapore: IACSIT Press, .

Naletina, D., \& Perkov, E. (2017). The

Economic Importance of Maritime Shipping With Special Reference on Croatia. $\mathrm{t}:$

https://www.researchgate.net/p ublication/324389577.

Rodrigue, J.-P. (2017). Maritime Transport. In D. Richardson, N. Castree, M. M. Goodchild, A. Kobayashi, W. Liu, \& R. A. Marston (Eds.), The International Encyclopedia of Geography. John Wiley \& Sons, Ltd. .

Santhanalaxmi, K., \& Chandramohan, S. (2020, June). Organizational Contention and Confrontation to Sustainable Development: A Socio-Economic Perspective. Shodh Sanchar Bulletin, 10(38).

Teshome, T. (2017). Challenges and Prospects of Applying Multi Modal Transportation System in Ethiopia: A Case Study in Ethiopian Shipping and Logistics Service Enterprise. Industrial Engineering Letters, 7(6), 10-25. 
Tuan, L. A., Vu, H. T., \& Nhan, N. L. (2018). Study of Satisfaction of Customers for the Quality of Sea Transport Services: Case in Tan Cang Shipping Joint Stock Company - Da Nang Branch. International Research Journal of Advanced Engineering and Science, 3(4), 220-224.

UNCTAD. (2019). Digitalization in Maritime Transport: Ensuring Opportunities For Development. United Nations Conference on Trade And Development. 75. UNCTAD. 